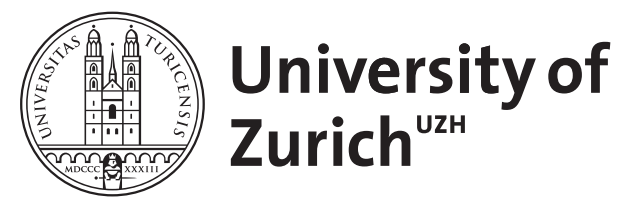

\title{
Job polarization and jobless recoveries
}

\author{
Jaimovich, Nir ; Siu, Henry E
}

\begin{abstract}
Job polarization refers to the shrinking share of employment in middle-skill, routine occupations experienced over the past 35 years. Jobless recoveries refers to the slow rebound in aggregate employment following recent recessions despite recoveries in aggregate output. We show how these two phenomena are related. First, essentially all employment loss in routine occupations occurs in economic downturns. Second, jobless recoveries in the aggregate can be accounted for by jobless recoveries in the routine occupations that are disappearing.
\end{abstract}

DOI: https://doi.org/10.1162/rest_a_00875

Posted at the Zurich Open Repository and Archive, University of Zurich ZORA URL: https://doi.org/10.5167/uzh-184745

Journal Article

Published Version

Originally published at:

Jaimovich, Nir; Siu, Henry E (2020). Job polarization and jobless recoveries. The Review of Economics and Statistics, 102(1):129-147.

DOI: https://doi.org/10.1162/rest_a_00875 


\title{
JOB POLARIZATION AND JOBLESS RECOVERIES
}

\author{
Nir Jaimovich and Henry E. Siu*
}

Abstract-Job polarization refers to the shrinking share of employment in middle-skill, routine occupations experienced over the past 35 years. Jobless recoveries refers to the slow rebound in aggregate employment following recent recessions despite recoveries in aggregate output. We show how these two phenomena are related. First, essentially all employment loss in routine occupations occurs in economic downturns. Second, jobless recoveries in the aggregate can be accounted for by jobless recoveries in the routine occupations that are disappearing.

\section{Introduction}

$\mathrm{I}_{\mathrm{s}}$ $\mathrm{N}$ the past 35 years, the U.S. labor market has seen the emergence of two new phenomena: job polarization and jobless recoveries. Job polarization refers to the increasing concentration of employment in the highest- and lowest-wage occupations as jobs in middle-skill occupations disappear. Jobless recoveries refer to periods following recessions in which rebounds in aggregate output are accompanied by much slower recoveries in aggregate employment. We argue that the emergence of jobless recoveries is linked to the job polarization process.

Consider first the phenomenon of job polarization. Acemoglu (1999), Autor, Katz, and Kearney (2006), Goos and Manning (2007), and Goos, Manning, and Salomons (2009), among others, document that employment is becoming concentrated at the tails of the occupational skill distribution. This process has accelerated since the 1980s, as per capita employment in middle-skill jobs disappears. This hollowing out of the middle is linked to the disappearance of occupations focused on routine tasks - activities that can be performed by following a well-defined set of procedures. Autor, Levy, and Murnane (2003) and the subsequent literature demonstrate that job polarization is primarily due to progress in technologies that substitute for labor in performing routine tasks. ${ }^{1}$

In this same time period, Gordon and Baily (1993), Groshen and Potter (2003), and Bernanke (2003, 2009), among others, discuss the emergence of jobless recoveries. In the past three recessions of 1991, 2001, and 2009, aggregate employment continues to decline for years following

Received for publication July 5, 2017. Revision accepted for publication October 4, 2018. Editor: Yuriy Gorodnichenko.

*Jaimovich: University of Zurich and CEPR; Siu: University of British Columbia and NBER

We thank David Andolfatto, Mark Aguiar, Susanto Basu, Paul Beaudry, Larry Christiano, Matias Cortes, Paul Gaggl, Erik Hurst, Marianna Kudlyak, Ryan Michaels, Richard Rogerson, Aysegul Sahin, Robert Shimer, Chris Taber, Marcelo Veracierto, Gianluca Violante, and numerous conference and seminar participants for helpful discussions, and the editor and anonymous referees for comments. Domenico Ferraro provided expert research assistance. H.E. thanks the Social Sciences and Humanities Research Council of Canada for support.

A supplemental appendix is available online at http://www.mitpress journals.org/doi/suppl/10.1162/rest_a_00875.

${ }^{1}$ See also Firpo, Fortin, and Lemieux (2014) and Goos, Manning, and Salomons (2014), regarding the relative role of technological change and outsourcing and offshoring in job polarization. the turning point in aggregate income and output. No consensus has yet emerged regarding the source of these jobless recoveries. $^{2}$

In this paper, we report two related findings. First, the disappearance of per capita employment in routine occupations associated with job polarization is not simply a gradual phenomenon; the loss is concentrated in economic downturns. Specifically, $88 \%$ of the job loss in these occupations since the mid-1980s occurs within a 12-month window of NBERdated recessions. A number of researchers have noted that the polarization process was accelerated by the Great Recession (see Autor, 2010, and Brynjolfsson \& McAfee, 2011). Our first point is that routine employment loss has happened almost entirely in the previous three recessions.

Our second, and main, point is that jobless recoveries in the aggregate can be accounted for by jobless recoveries in the routine occupations that are disappearing. This is based on three facts. First, employment in the routine occupations identified by Autor et al. (2003), Autor and Dorn (2013), and others accounts for a significant fraction of aggregate employment; averaged over the jobless recovery era, these jobs account for about $50 \%$ of total employment. Second, essentially all of the contraction in per capita aggregate employment during NBER-dated recessions can be attributed to recessions in these middle-skill, routine occupations. Third, jobless recoveries are observed only in these disappearing, middle-skill jobs. The high- and low-skill occupations to which employment is polarizing either do not experience contractions or, if they do, rebound soon after the turning point in aggregate output. Hence, jobless recoveries can be traced to the disappearance of routine occupations in recessions. Finally, it is important to note that jobless recoveries were not observed in routine occupations - or in aggregate employment-prior to the era of job polarization.

In section II, we present data on jobless recoveries and job polarization. In section III, we present data documenting that these two phenomena are related. In section IV, we discuss additional evidence regarding the link between the decline of employment in routine occupations and jobless recoveries. Section V concludes.

\section{Two Labor Market Phenomena}

\section{A. Jobless Recoveries}

Figures 1 and 2 plot the cyclical behavior of aggregate per capita employment in the United States during the past six recessions and subsequent recoveries. ${ }^{3}$ Aggregate per capita

\footnotetext{
${ }^{2}$ See, for instance, Koenders and Rogerson (2005), Bachmann (2012), and Berger (2012) for recent theoretical work.

${ }^{3}$ The 1980 recession is omitted since it is followed closely by a recession beginning in 1981, limiting our ability to study its recovery.
} 
Figure 1.-Aggregate EMployment around EARLy NBER ReCESSIONS
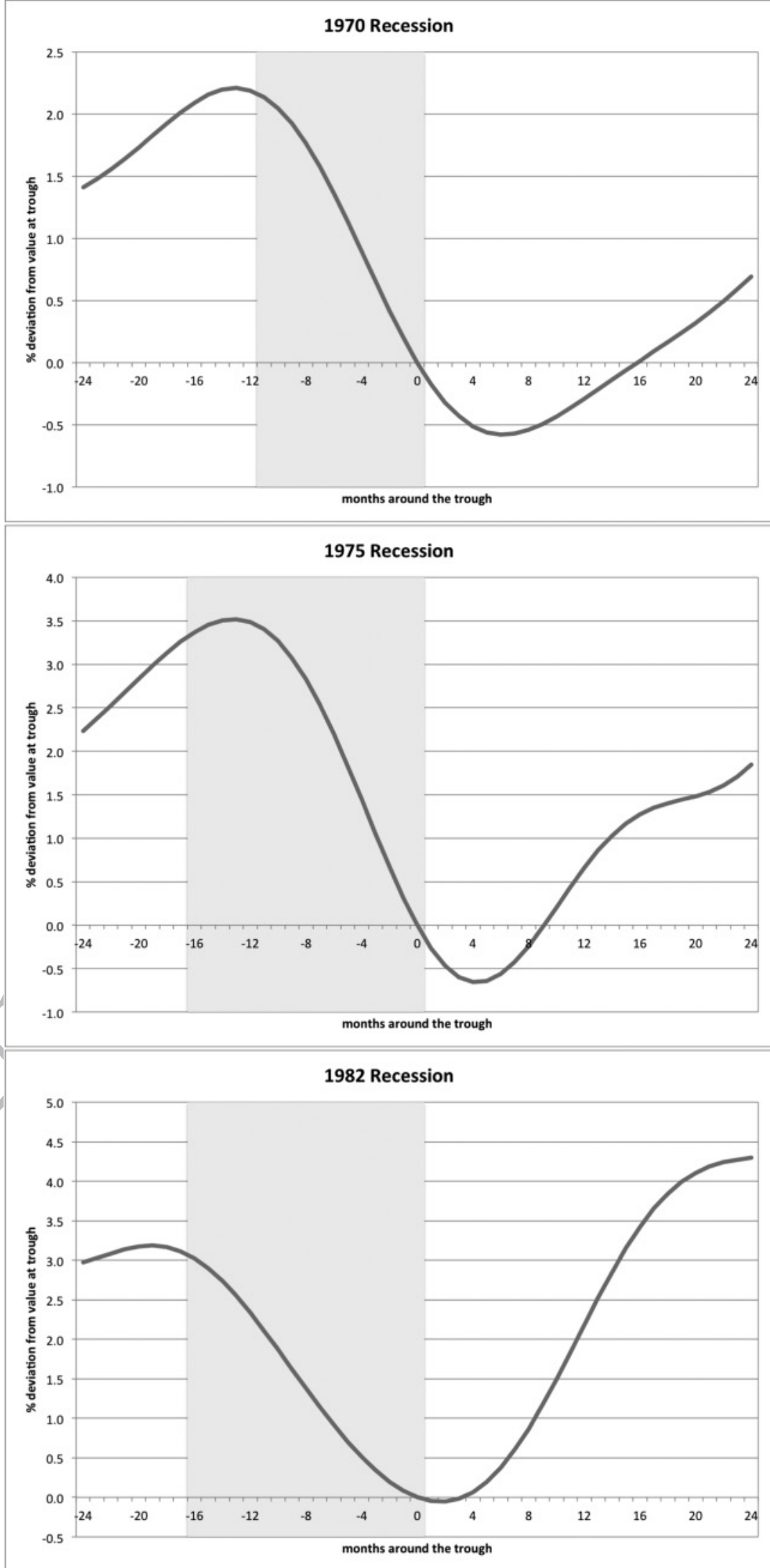

Data from the Bureau of Labor Statistics, CPS. See appendix A for details. 
Figure 2.-Aggregate EMPLOYMent ARound RecEnt NBER ReCESSIONS

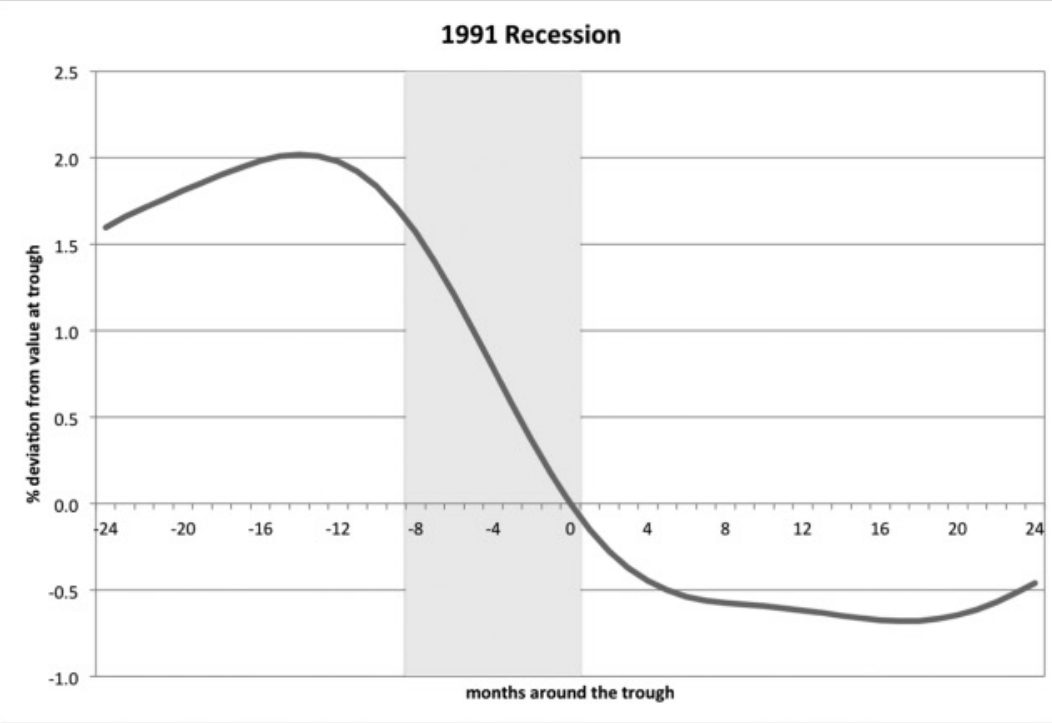

2001 Recession
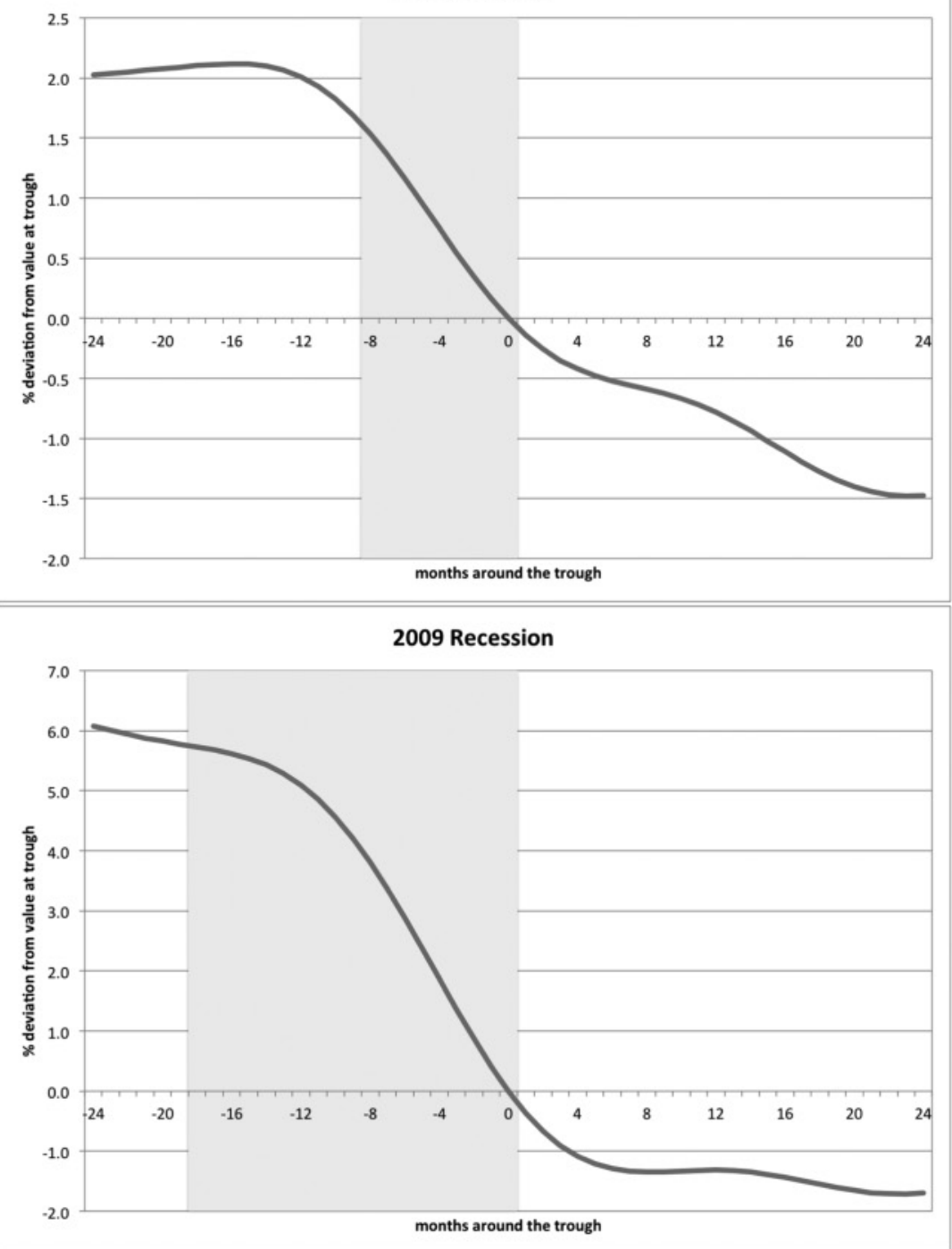

Data from the Bureau of Labor Statistics, CPS. See appendix A for details. 
employment is that of all civilian noninstitutionalized individuals aged 16 years and over (seasonally adjusted), normalized by the population. ${ }^{4}$ Throughout the paper, recessions are referred to by their trough year; for example, the recession that began in December 2007 and ended in June 2009 is referred to as the 2009 recession. Because the monthly employment data are noisy, the data are logged and bandpassfiltered to remove only fluctuations at frequencies higher than 18 months (business cycle fluctuations are traditionally defined as those between frequencies of 18 and 96 months). ${ }^{5}$ On the $x$-axis of each figure, the trough of the recession, as identified by the NBER, is indicated as date 0 ; we plot data for two years around the trough date. The shaded regions indicate the NBER peak-to-trough periods. Employment is normalized to 0 at the trough of each recession. Hence, the $y$-axis measures the percent change in employment relative to its value in the NBER trough.

Figure 1 displays the 1970, 1975, and 1982 recessions. In each case, aggregate employment begins to expand within six months of the trough. The fact that employment recovers within two quarters of the turning point in aggregate output and income is typical of the business cycle prior to the mid-1980s (see, e.g., Schreft \& Singh, 2003, and Groshen \& Potter, 2003).

This contrasts sharply from the 1991, 2001, and 2009 recessions. As displayed in figure 2 , these recoveries were jobless: despite expansions in other measures of economic activity, such as real GDP (RGDP) and real gross domesticincome, following the trough, aggregate per capita employment continued to contract for many months. In 1991, employment continues to fall for 17 months past the trough before turning around; employment does not reach its prerecession level until five years later, in 1996. In 2001, employment falls for 23 months past the trough before turning around; it does not return to its prerecession level before the subsequent recession. Following the Great Recession of 2009, employment takes 23 months to begin recovery. Hence, the jobless recovery is a phenomenon characterizing recent recessions (see also Groshen \& Potter, 2003, and Bernanke, 2003).

Table 1 summarizes these differences, presenting several measures of the speed of recovery following early and recent recessions. Panel A concerns the recoveries in aggregate per capita employment. The first row lists the number of months it takes for employment to turn around (stop contracting), rel-

\footnotetext{
${ }^{4}$ Data are taken from the Labor Force Statistics of the CPS, downloaded from the BLS website (bls.gov/data/). See appendix A for a detailed description of all data sources. Employment data at the aggregate and occupational level are available dating back to 1959 . Issues with the early CPS data, especially during the 1961 recession, are well documented; see, for instance, the President's Committee to Appraise Employment and Unemployment Statistics report, "Measuring Employment and Unemployment," commonly referred to as the Gordon report. The report's recommendations led to methodological changes adopted by the BLS in 1967 (see Stein, 1967). As such, our analysis uses data beginning in July 1967.

${ }^{5} \mathrm{We}$ implement this using the bandpass filter proposed by Christiano and Fitzgerald (2003), who discuss the merits of their method for isolating fluctuations outside the traditional business cycle frequencies and near the end points of data sets.
}

Table 1.-Measures of Recovery following EARly and Recent RECESSIONS

\begin{tabular}{|c|c|c|c|c|c|c|}
\hline & \multicolumn{3}{|c|}{ Early } & \multicolumn{3}{|c|}{ Recent } \\
\hline & 1970 & 1975 & 1982 & 1991 & 2001 & 2009 \\
\hline \multicolumn{7}{|l|}{ A. Employment } \\
\hline Months to turn around & 6 & 4 & 2 & 17 & 23 & 23 \\
\hline Months to trough level & 16 & 10 & 4 & 31 & 55 & 76 \\
\hline Half-life (in months) & 27 & 23 & 10 & 38 & NA & NA \\
\hline \multicolumn{7}{|l|}{ B. Output } \\
\hline Months to turn around & 0 & 0 & ) & 0 & 0 & 0 \\
\hline Months to trough level & 0 & 0 & & 0 & 0 & 0 \\
\hline Half-life (in months) & 7 & 10 & & 9 & 3 & 15 \\
\hline
\end{tabular}

Data from the CPS; Bureau of Economic Analysis, National Income and Product Accounts, and James Stock and Mark Watson. See appendix A for details.

ative to the NBER trough date. The second row indicates the number of months it takes from the trough date for employment to return to its level at the trough. The third row lists a "half-life" measure: the number of months it takes from the trough date to regain half of the employment lost during the NBER-defined recession.

That there has been a marked change in the speed of employment recoveries is obvious. Averaged over the three early recessions, employment turns around approximately 4 months after the NBER trough date; in the recent recessions, the average turnaround time is 21 months. Averaged over the early recessions, employment returns to its trough level within approximately 10 months. Over the three recent recessions, this value is 54 months, taking almost 6.5 years to return to its trough following the Great Recession. Finally, while it takes at most 27 months from the trough date to regain half of the employment lost in the three early recessions, it takes at least 38 months in the recent recessions. Indeed, employment never regained half of its loss following the 2001 recession and has yet to do so after the Great Recession.

This contrasts with the nature of recoveries in aggregate output. Panel B in table 1 presents the same recovery measures for per capita RGDP. To obtain monthly measures, we use the monthly data of Stock and Watson (see appendix A for details). Given the NBER Dating Committee's emphasis on RGDP and real gross domestic income in determining cyclical turning points, it is perhaps not surprising that aggregate output begins recovery on the NBER trough dates (see nber.org/cycles/recessions_faq.html). This is true for both the early and recent recessions, as indicated by the first two rows of panel B. In the early recessions, it takes on average seven months from the trough date for output to regain half of its recessionary loss; in recent recessions, the average time taken is nine months, only slightly greater. ${ }^{6}$ Hence, there has been no marked change in the speed of recovery for aggregate output across early and recent recessions. The differences in the speed of recovery in employment following recent recessions,

\footnotetext{
${ }^{6}$ Because the monthly RGDP estimates of Stock and Watson are "noisy," the data are bandpass-filtered to remove fluctuations at frequencies higher than eighteen months (as with the employment data) in producing the halflife statistics.
} 
without corresponding differences in the recovery speed of output, characterize the jobless recovery phenomenon.

\section{B. Job Polarization}

The structure of employment has changed dramatically in the past 35 years. One of the most pervasive aspects of change has been within the occupational wage distribution: employment has become polarized, with employment share shifting away from middle-skill occupations toward both the highand low-skill tails of the distribution (see, e.g., Acemoglu \& Autor, 2011).

To see this, we disaggregate total employment by occupational groups. Appendix A discusses the occupational classification in detail; online appendix A discusses the robustness of our results to alternative classifications used in the literature. For brevity, we include a summary here. Following Acemoglu and Autor (2011), we delineate occupations along two dimensions: "cognitive" versus "manual" and "routine" versus "nonroutine." These delineations are based on the skill content of the tasks performed in the occupation. The distinction between cognitive and manual jobs is straightforward, characterized by differences in the extent of mental versus physical activity. The distinction between routine and nonroutine jobs is based on the work of Autor et al. (2003). If the tasks involved can be summarized as a relatively small set of specific activities accomplished by following well-defined instructions and procedures, the occupation is considered routine. If instead the job entails a larger number of tasks requiring flexibility, creativity, problem/solving, or human interaction skills, the occupation is nonroutine.

In this delineation, nonroutine cognitive occupations include managerial, professional, and technical workers, such as physicians, public relations managers, financial analysts, computer programmers, and economists. Routine cognitive occupations are those in sales andin office and administrative support-for example, secretaries, bank tellers, retail salespeople, travel agents, mail clerks, and data entry keyers. Routine manual occupations are blue-collar jobs, such as machine operators and tenders, mechanics, dressmakers, fabricators and assemblers, and meat processing workers. Nonroutine manual occupations are service jobs, including janitors, gardeners, manicurists, bartenders, home care aides, and personal care workers.

These classifications correspond to rankings in the occupational wage distribution. Nonroutine cognitive occupations tend to be high-skill occupations and nonroutine manual occupations low skilled. Routine jobs, both cognitive and manual, tend to occupy the middle of the occupational wage distribution (see, e.g., Autor, 2010; Firpo et al., 2014; and Goos et al., 2014). Given this, we combine the routine cognitive and routine manual occupations into one group. ${ }^{7}$

\footnotetext{
${ }^{7}$ For brevity, the analogs of all of our figures with the routine occupations split into two groups can be found in an earlier version of this paper, available at http://faculty.arts.ubc.ca/hsiu/research/polar20120331.pdf. None of our
}

Figure 3 displays data relating to job polarization. We present data by decade, as is common in the literature (Autor, 2010), except the final bar covering the fifteen-year period 2002 to 2017. Each bar represents the percent change in an occupation group's share of total employment, from the starting year to the terminal year, using annual averages. Over time, the share of employment in high-skill (nonroutine cognitive) and low-skill (nonroutine-manual) jobs has been growing. This has been accompanied by a hollowing out of the middle-skill, routine occupations. Hence, there has been a polarization in employment away from routine, middle-skill jobs toward nonroutine cognitive and manual jobs. In 1982, routine occupations accounted for approximately $56 \%$ of total employment; in 2017, this share had fallen to $42 \%$.

\section{Linking the Two Phenomena}

\section{A. Occupational Employment: Long-Run Dynamics}

As noted, job polarization involves the long-term decline in employment in routine occupations as a share of total employment. This declining share can be due to decreases in routine employment (in the numerator), increases in nonroutine employment (denominator), or both. We find an important change in the dynamics of routine employment during the job polarization era. Given our interest in jobless recoveries in per capita aggregate employment, documented in section IIA, the decline of per capita employment in routine occupations is the primary object of interest throughout our analysis. We ask how this process has unfolded over time: whether the losses have occurred gradually, or whether they are bunched up within certain time intervals. Figure 4 displays time series for per capita employment in the three occupational groups of figure 3 at a monthly frequency from July 1967 to December 2017.

As is evident from the figure, both of the nonroutine occupational groups are growing over time. Per capita employment in nonroutine cognitive occupations displays a $59 \log$ point increase during this period. After declining from 1967 to 1973 , nonroutine manual employment displays a $17 \mathrm{log}$ point increase. Recessions have temporarily halted these occupations' growth to varying extents but have not abated the upward trends.

This stands in stark contrast to the routine occupational group. In per capita terms, routine employment was relatively constant until the late 1980s and fell $29 \log$ points from the local peak in 1990 to 2017.

The growth of per capita employment in nonroutine jobs (coupled with the lack of growth in routine jobs) makes it clear that the share of employment in routine occupations has been in decline since at least 1967 . Hence, what differentiates the job polarization era that began in the 1980s is the obvious acceleration in the relative decline of routine employment.

substantive results are changed when considering the routine cognitive and manual occupations separately. 
Figure 3.-Percent Change in Employment Shares by Occupation Group

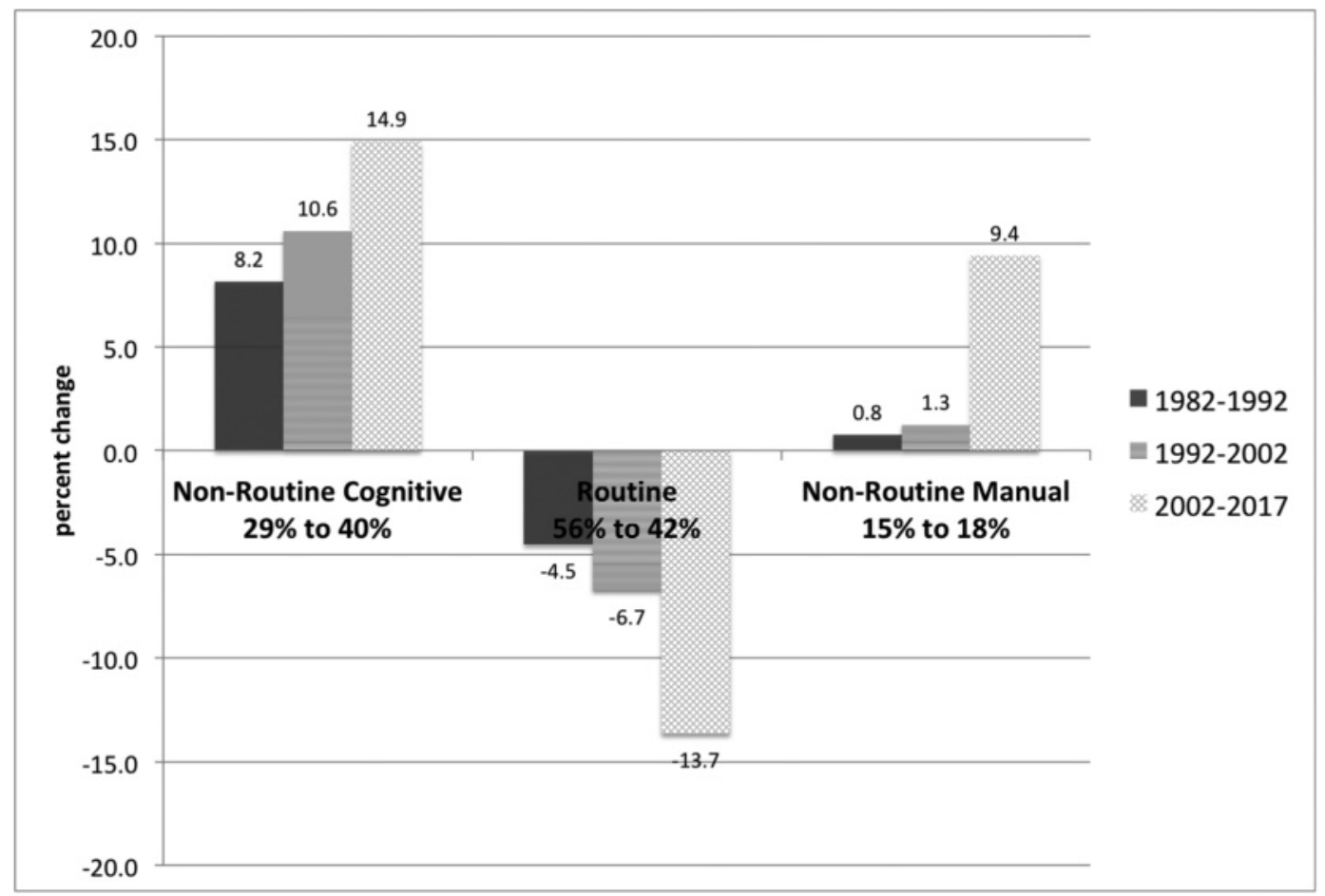

This acceleration is due to the fact that per capita routine employment is disappearing in level terms.

What is equally clear in figure 4 is that routine job loss has not occurred steadily during the past 35 years. The decline is concentrated in economic downturns, which occurred in essentially three steps. Following its peak in 1990, per capita employment in these occupations fell $3.5 \%$ to the trough of the 1991 recession and a further $1.8 \%$ during the subsequent jobless recovery. After a minor rebound, employment was essentially flat until the 2001 recession. In the two-year window around the 2001 trough, this group shed $6.2 \%$ of its employment before leveling off again. Routine employment plummeted again in the Great Recession-11.3\% in the two-year window around the trough — with no subsequent recovery, quite obviously.

To state this slightly differently, $88 \%$ of the $29 \log$ point fall in per capita routine employment that occurred from 1990 to 2017 occurred within a twelve-month window of NBER recessions (six months prior to the peak and six months after the trough). Hence, this stark aspect of job polarization is observed during recessions.

\section{B. Occupational Employment: Business Cycle Snapshots}

In the job polarization era, per capita employment in routine occupations disappeared during recessions. Moreover, as figure 4 makes clear, prior to the disappearance of routine occupations, routine employment always recovered following recessions. In this section, we investigate whether this change in the dynamics of routine employment has contributed to the jobless recoveries following the three recent recessions. This is quantitatively plausible since routine occupations account for a substantial fraction of aggregate employment.

To do this, we zoom in on recessionary episodes. Figures 5 and 6 plot per capita employment for the routine and nonroutine occupational groups around NBER recessions. These figures are constructed in the same manner as figures 1 and $2 .^{8}$

Figure 5 displays the early recessions of 1970, 1975, and 1982 and their subsequent recoveries. Contractions in employment are clearly observed in the routine occupations. In the nonroutine occupational group, employment was either flat or growing during these recessions and recoveries. Hence, the contractions in per capita aggregate employment displayed in figure 1 are due almost exclusively to the routine occupations; this is true despite the fact that routine occupations account for only 58\% of total employment, averaged over the 1967-1982 period. Measuring from NBER peak to trough, 97\% of all per capita job loss in both the 1970 and 1975 recessions was accounted for by job loss in routine occupations. In the 1982 recession, job loss in routine occupations accounted for $145 \%$ of the aggregate as employment actually grew in the nonroutine group.

Moreover, no jobless recoveries were observed in the routine occupational group in these early episodes. Following these recessions, routine employment begins recovering

\footnotetext{
${ }^{8}$ For the analogous figures with the nonroutine cognitive and nonroutine manual groups displayed separately, see online appendix A.
} 
Figure 4.-EMPLOYMENT IN OCCUPATIONAL GROUPS, 1967-2017
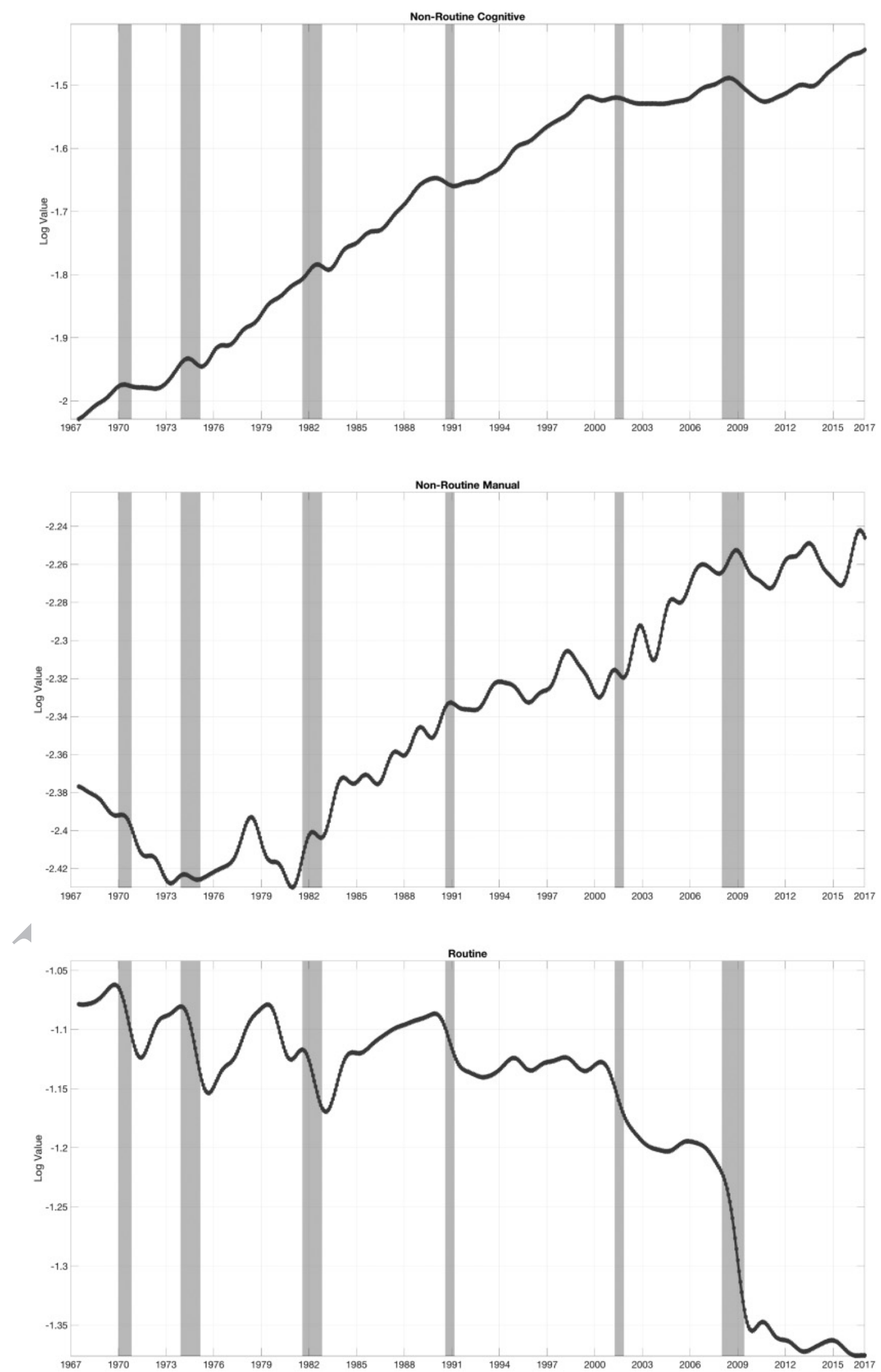
Figure 5.-OCCUPATIONAL EMPLOYMENT AROUND EARLY NBER ReCESSIONS

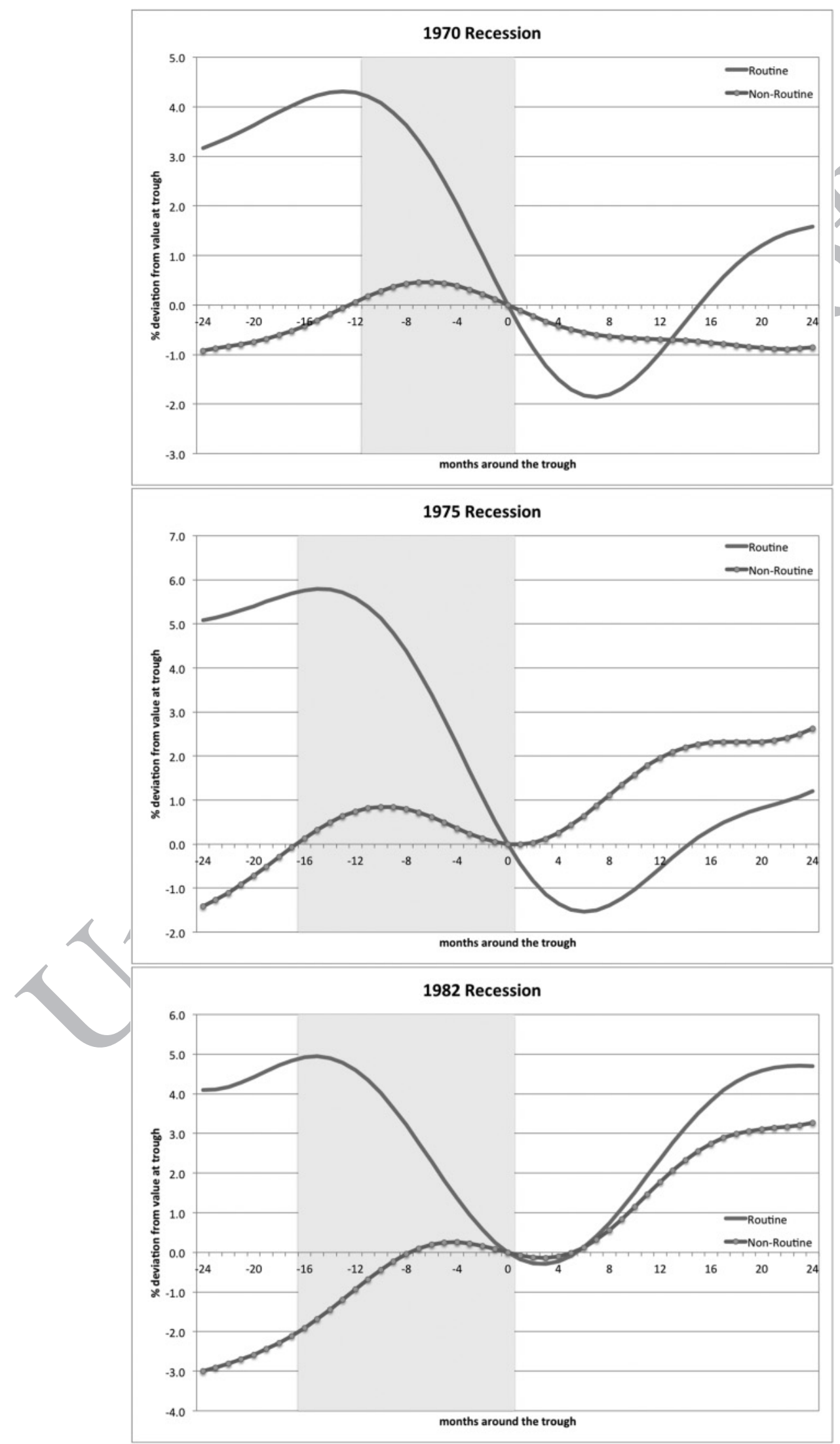

Data from the CPS. See appendix A for details. 
Figure 6.-OCCupational EMPLOYMENT AROUND ReCENT NBER ReCESSIONS
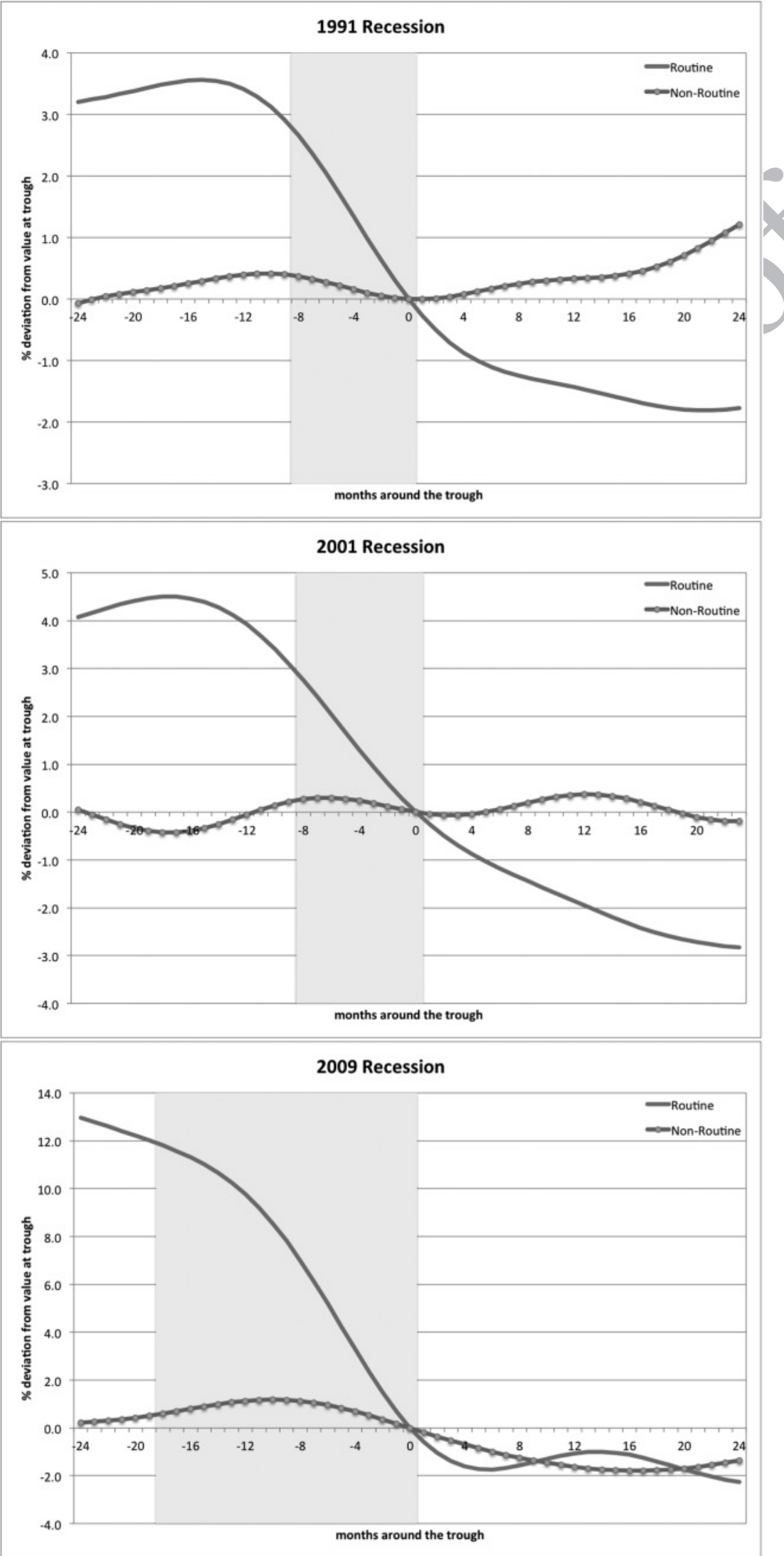
within seven months of the trough. This mirrors the lack of jobless recoveries at the aggregate level displayed in figure 1. Comparing figures 1 and 5, it is clear that the cyclical dynamics of aggregate employment in the 1970, 1975, and 1982 episodes are driven by the dynamics of routine employment.

Comparing figures 2 and 6, it is again clear that the recession and recovery dynamics of aggregate employment in 1991, 2001, and 2009 mirror the dynamics of routine employment. Consider, for instance, the 1991 recession displayed in the uppermost panels. In the 15 months prior to the trough, per capita aggregate employment falls by $2.0 \%$ and falls a further $0.5 \%$ during the 24-month window after the recession displayed in figure 2. Figure 6 indicates that this pattern is not exhibited in nonroutine occupations. During this time window, per capita nonroutine employment rises, with only a mild $(0.4 \%)$ contraction and clear recovery beginning on the NBER trough date. ${ }^{9}$ Only routine employment exhibits the same pattern as in the aggregate, with a $3.5 \%$ fall in the 15 months prior to the trough, and a further $1.8 \%$ decline in the 24-month recovery period.

Indeed, figure 6 indicates that routine occupations experience jobless recoveries in all three of the recent episodes. Per capita routine employment experiences clear contractions during each recession. As with the early episodes, these occupations account for the bulk of the contraction in aggregate employment. In the 1991, 2001, and 2009 recessions, routine jobs account for $89 \%, 91 \%$, and $94 \%$ of all job loss, respectively. This is despite the fact that routine occupations account for approximately $51 \%$ of total employment, averaged between 1983 and 2011 (two years following the 2009 recession).

More important, routine occupations show no recoveries in figure 6. As discussed above, per capita employment in routine occupations falls a further $1.8 \%$ in the 24 months following the end of the 1991 recession. A similar picture emerges for the 2001 recession: large employment losses leading up to the trough are followed by a further $2.8 \%$ loss afterward. In 2009 , these occupations are hit especially hard, falling $11.8 \%$ from the NBER peak to trough and a further $2.3 \%$ in the two years after. Indeed, per capita routine employment shows no recovery to date, down $3.9 \%$ from the recession's trough to December 2017.

To summarize, jobless recoveries are evident in only the three most recent recessions and are clearly evident only in routine occupations. In this occupational group, employment never recovers-in the short, medium, or long term. These occupations are disappearing. ${ }^{10}$ By contrast, nonroutine occupations either experience no contractions or only mild

\footnotetext{
${ }^{9}$ We note, however, that the average recovery of nonroutine employment following the three recent recessions is slower than that of the early recessions. This is due in part to the fact that nonroutine employment actually grew during the 1982 recession, and to the slow recovery following the Great Recession. We return to this latter point below.

${ }^{10}$ For further analysis of this process in terms of worker gross flows (job creation/separation, occupational switching), see Cortes (2016) and Cortes et al. (2016).
}

contractions during recessions, and no jobless recoveries afterward. In this sense, the jobless recovery phenomenon is accounted for by the disappearance of routine jobs.

\section{A Counterfactual Exercise}

To make this final point clear, we perform a simple accounting exercise to investigate the role of the disappearance of routine employment in accounting for jobless recoveries. This is informative since recessions in aggregate employment are due almost entirely to recessions in routine occupations. We ask what would have happened in recent recessions if the postrecession behavior of employment in routine occupations had looked more similar to the early recessions. Would the economy still have experienced jobless recoveries in the aggregate? ${ }^{11}$

For the 1991, 2001, and 2009 recessions, we replace the per capita employment in routine occupations following the trough with their average response following the troughs of the 1970,1975 , and 1982 recessions. We do this in a way that matches the magnitude of the fall in employment after each recent recession but follows the time pattern of the early recessions. In particular, we ensure that the turning point in routine employment comes five months after the trough, as in the average of those recoveries. We then sum up the actual employment in nonroutine occupations with the counterfactual employment in routine occupations to obtain a counterfactual aggregate employment series. The behavior of these counterfactual series around the recent NBER trough dates is displayed in figure 7. Further details regarding the construction of the counterfactuals are discussed in appendix B.

Figure 7 makes clear that had it not been for the disappearance of routine jobs that occurs during recessions, we would not have observed jobless recoveries. Aggregate employment would have experienced clear turning points five, five, and seven months after the troughs of the 1991, 2001, and 2009 recessions, respectively. In the 1991 and 2001 recessions, employment would have exceeded its value at the NBER-dated trough within ten months. In the case of the 2009 recession, recovery back to the trough level would have taken eighteen months. This is due to the fact that the most recent, and far more severe, recession was experienced more broadly across occupations and because routine employment represents a shrinking share of total employment over time. Interestingly, while employment in nonroutine occupations suffered only mild contraction during the recession (falling $1.1 \%$ in the ten months prior to the trough), it continued to contract by $1.8 \%$ in the sixteen months following the NBER trough date. Hence, the malaise in the labor market following the 2009 recession is, unsurprisingly, not solely accounted for by routine occupations given the nature of the Great

\footnotetext{
${ }^{11}$ In spite of the results presented in section IIIB, the answer to this is not immediate since in the jobless recovery era, routine jobs account for only $50 \%$ of aggregate employment. Reversing jobless recoveries in routine employment may not be enough, quantitatively, to reverse them in the aggregate.
} 
Figure 7.-Actual and Counterfactual Employment around ReCent NBER Recessions
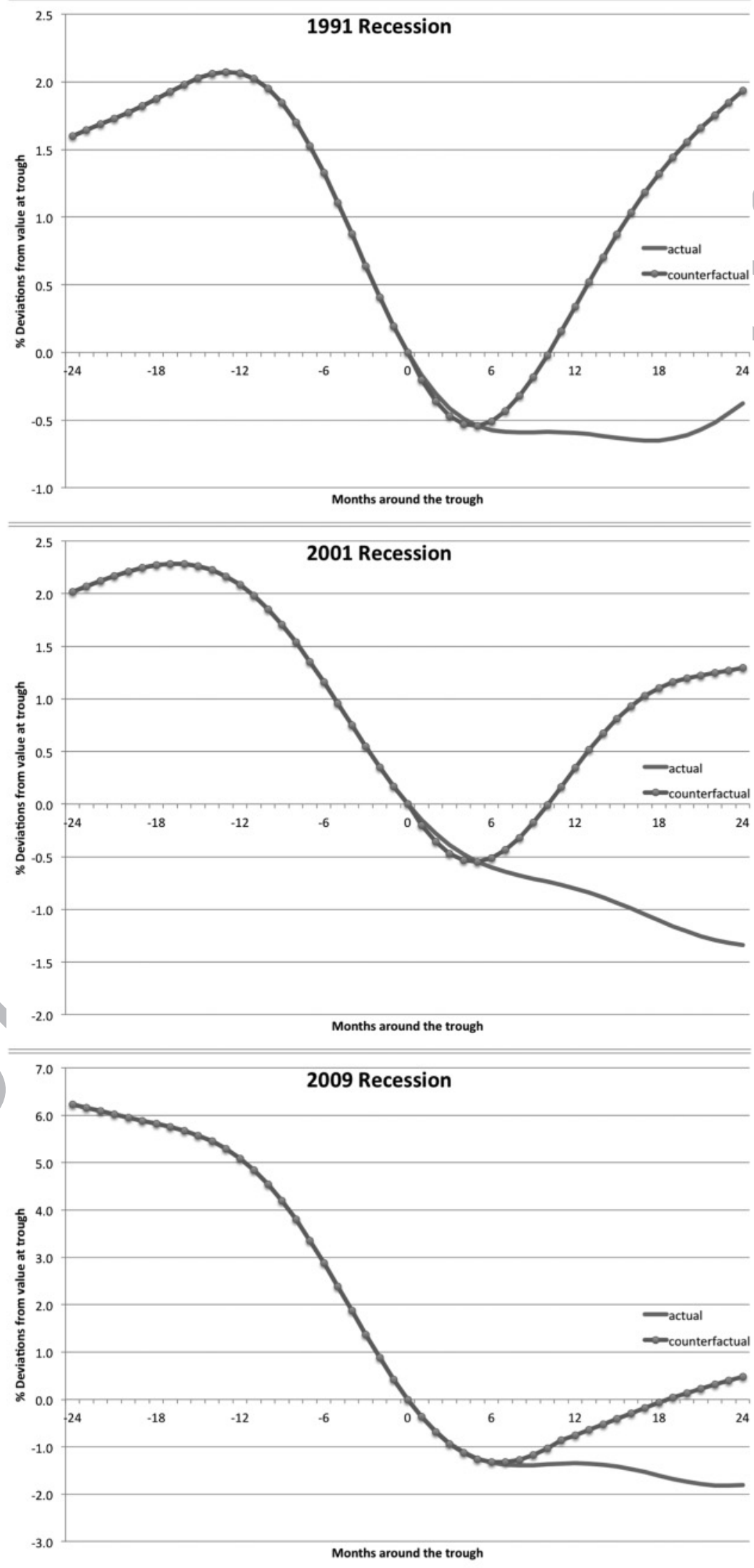
Recession. Nonetheless, the counterfactual exercise indicates that employment would have recovered, as opposed to declining in the 24 months following the end of the recession.

We note again that jobless recoveries cannot be accounted for by a change in the postrecession behavior of employment in nonroutine occupations. This is perhaps not surprising given that the dynamics of nonroutine employment play little role in that of aggregate employment during recessions. Nonetheless, we have performed the same counterfactual as above, but replacing the employment response in nonroutine occupations following the recent recessions with their average response following the early ones. Though not displayed for brevity, we find that this generates no clear recovery in aggregate employment beyond its trough value in any of the recent episodes. By contrast, aggregate employment recovers beyond its trough value within ten, ten, and eighteen months in the 1991, 2001, and 2009 episodes, respectively, in the counterfactual with routine employment.

\section{Further Discussion}

Here we offer a few points of clarification regarding job polarization and jobless recoveries by discussing the role of the goods-producing industries and educational composition in accounting for these two phenomena. Online appendix A contains additional discussion on the robustness of our key results to further disaggregation of routine occupations into cognitive and manual components and alternative categorizations of routine occupations.

Manufacturing and construction. This paper emphasizes the recession and recovery dynamics of routine employment. Given this, it is possible that our emphasis on routine occupations is simply a relabeling of dynamics in the cyclically sensitive goods-producing industries, manufacturing and construction. This, however, is not the case.

Consider the three early recessions of 1970, 1975, and 1982. Taking a simple average across these recessions, manufacturing and construction accounted for $82 \%$ of the aggregate per capita employment lost from NBER peak to trough. Averaging across the three recent recessions of 1991, 2001 , and 2009 , only $50 \%$ of total job loss was accounted for by these industries. So while the goods-producing industries account for a disproportionate fraction of recessionary job losses, it is clear that a significant fraction occurs in service production as well, and especially recently. But as discussed in section IIIB, routine occupations accounted for $113 \%$ and $91 \%$ of aggregate job loss when averaged across the three early and three recent recessions, respectively. Hence, categorizing across goods- and serviceproducing industries provides a somewhat useful distinction in studying cyclical fluctuations in employment. But a more valuable categorization —one that perhaps has not been sufficiently appreciated within macroeconomics - exists in distinguishing between routine and nonroutine occupations: reces- sionary job loss is experienced across all industries, namely in routine occupations across industries.

More specifically, it is possible that the phenomena of job polarization and jobless recoveries simply reflect the employment dynamics of manufacturing and construction. It is well known that manufacturing employment is more "routine intensive" compared to the economy as a whole. Following the Great Recession, for instance, the routine occupation share of manufacturing employment is $68 \%$, as compared to $44 \%$ economy-wide. And employment in manufacturing, during both the early and recent recessions, follows a similar pattern to that of routine occupations (across all industries). Manufacturing employment displayed strong cyclical rebounds prior to the mid-1980s; in the three recent recessions, employment has failed to recover following rebounds in manufacturing (and aggregate) output.

We first note that job loss in manufacturing accounts for only a fraction of the job loss in routine occupations. Across all industries, routine employment has fallen $29 \log$ points from 1990 to 2017, as displayed in figure 4. In levels, this reflects a per capita employment loss of 0.081. But manufacturing aside, all other sectors of the economy have also experienced a pronounced loss of routine jobs. Routine employment in sectors outside manufacturing has fallen $22 \mathrm{log}$ points during the same period. This represents a per capita employment loss of 0.051 . Hence, manufacturing accounts for only $0.03 / 0.081=37 \%$ of the observed routine job loss. This point has also been made by Autor et al. (2003) and Acemoglu and Autor (2011), who demonstrate that job polarization is due largely to shifts in occupational composition (away from routine toward nonroutine jobs) within industries, as opposed to shifts in industrial composition (away from routine-intensive towards nonroutine-intensive industries).

Second, jobless recoveries experienced in the past 35 years cannot be explained simply by jobless recoveries in the manufacturing sector. While the postrecession behavior of employment in manufacturing mimics that of routine occupations, it plays only a small part in generating jobless recoveries. This is because manufacturing accounts for a quantitatively small share of total employment (approximately $18 \%$ in the mid-1980s and less than $10 \%$ at present). To demonstrate this, figure 8 performs the same counterfactual exercise for the manufacturing industry as figure 7 does for routine occupations. In each of the three jobless recoveries, we replace the employment response in manufacturing following the trough with their average response following the troughs of the early recessions. We then sum up the actual employment in nonmanufacturing industries with the counterfactual employment in manufacturing to obtain a counterfactual per capita aggregate employment series.

Figure 8 displays the behavior of these counterfactual series around the 1991, 2001, and 2009 NBER trough dates. Eliminating the jobless recovery in manufacturing implies that following the 1991 recession, aggregate employment returns to its level at the trough after 23 months, as opposed to 
Figure 8.-Actual and Counterfactual Employment around Recent NBER Recessions: The Manufacturing CaSe
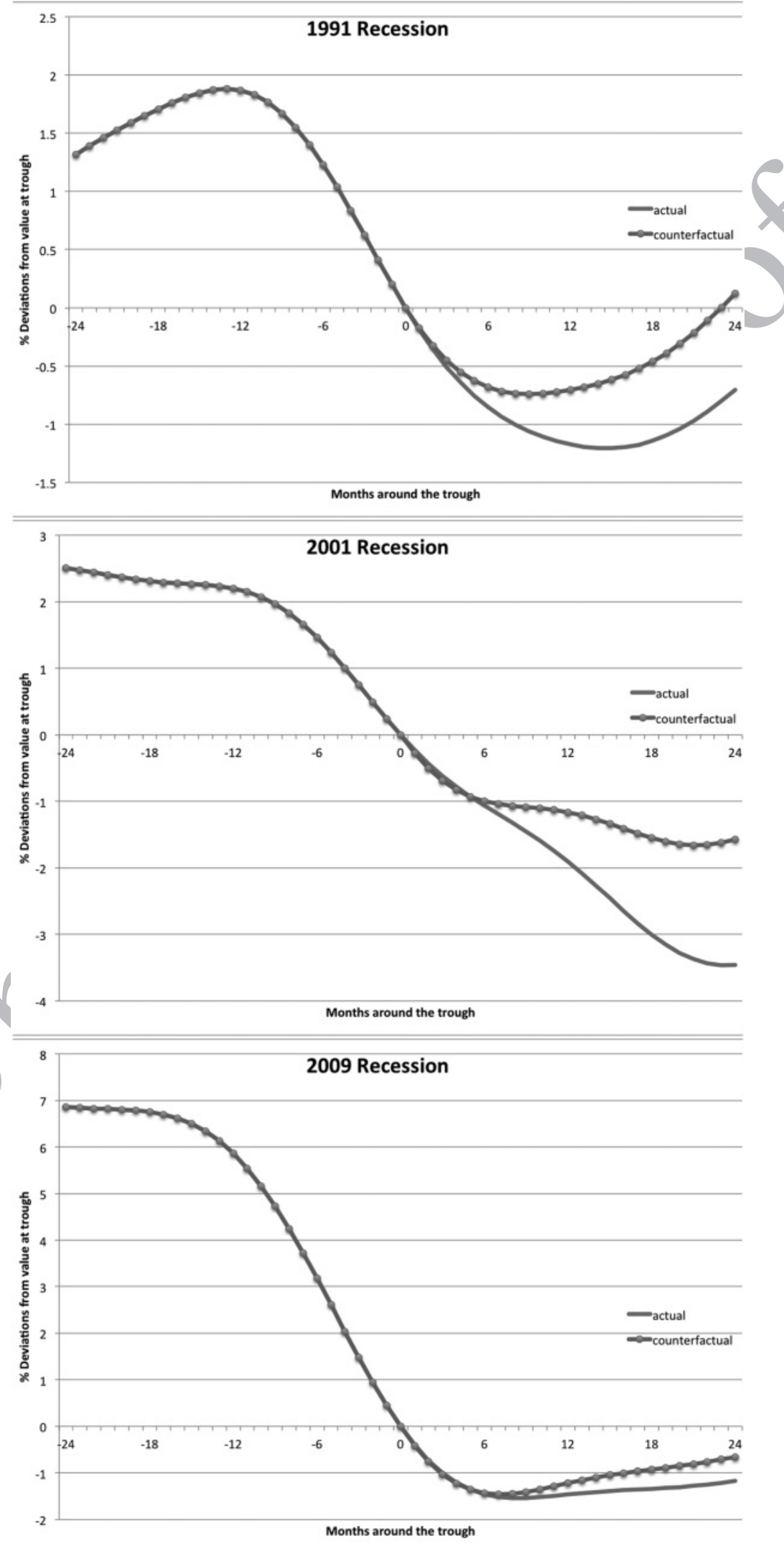
the 31 months observed in the data. This is still appreciably longer than the average of 10 months required in the early recoveries. Following the 2001 and 2009 recessions, altering the recovery in manufacturing has even less impact. Aggregate employment would still have been below the value at the trough, a full 24 months after the recession ended. Jobless recoveries would still have been observed following each recessionary episode. This evidence is consistent with the findings of Aaronson et al. (2004), who find that jobless recoveries cannot be explained by structural change at the industry level.

Finally, we note that neither phenomena are due to employment dynamics in construction. Of the total job losses in routine occupations from 1990 to 2017, only 6\% are accounted for by construction. And while not displayed here for brevity, we have performed the same counterfactual experiment for the construction industry that figure 8 does for manufacturing. Following each of the recent recessions, replacing the employment response in construction with their average response following the early recessions has almost no effect on per capita aggregate employment. Construction plays essentially no role in accounting jobless recoveries since the industry accounts for a very small share (approximately 5\%) of total employment. ${ }^{12}$

Education. Here, we clarify the role of education in accounting for the decline of routine employment and jobless recoveries. The share of low-educated workers in the labor force (those with high school diplomas or less) has declined in the past 35 years, and these workers exhibit greater business cycle sensitivity than those with higher education. It is thus possible to conjecture that the terms routine and low education are interchangeable. In what follows, we show that this is not the case.

In particular, it is true that education is correlated with occupation. However, as Acemoglu and Autor (2011) discussed, educational attainment is more closely aligned with the distinction between cognitive versus manual occupations, with high- (low-) educated workers tending to work in cognitive (manual) jobs. As such, job polarization-the disappearance of employment in routine occupations relative to nonroutine occupations - cannot be explained simply by the change in educational composition. Consider the case of high school graduates, who make up the majority of low-educated workers. In levels, their per capita employment has fallen 0.059 from 1990 to present. However, this fall is highly concentrated, with $91 \%$ of the loss occurring in routine occupations. In contrast, employment among high school graduates in nonroutine jobs has remained essentially constant, falling by only 0.008 during the polarization period. ${ }^{13}$

\footnotetext{
${ }^{12}$ See also Charles, Hurst, and Notowidigdo (2019) for a discussion of housing and manufacturing employment during the most recent business cycle boom and bust.

${ }^{13}$ The importance of the routine/nonroutine distinction is further illustrated by the "some college" group - those with more than high school attainment but less than a college degree. Per capita employment in
}

Similarly, jobless recoveries are not simply a phenomenon reflecting the postrecession dynamics of low education employment. In particular, business cycle fluctuations for high school educated workers differ greatly across occupational groups. For these workers, per capita employment in routine occupations fell $3.6 \%, 4.0 \%$, and $13.2 \%$ in the 1991, 2001, and 2009 recessions, respectively. And indeed, it is this group that is disappearing and not recovering. Averaged across the three recessions, employment is down a further $1.5 \%$ from the level at the NBER trough, a full 24 months into the economic recovery. By contrast, employment of high school graduates in nonroutine occupations experienced extremely mild contractions - of $0.9 \%, 0.2 \%$, and $0.5 \%$ in the three recent recessions-and no long-term disappearance. Thus, among these low-educated workers, jobless recoveries are to be found only in routine occupations.

\section{Further Evidence}

In section III, we exploit time series variation across the pre- and postjob polarization eras to demonstrate the role of the decline in routine occupations in jobless recoveries: prior to the long-run decline in per capita routine employment, jobless recoveries did not occur; jobless recoveries have emerged since the decline in employment in these occupations. In addition, the role attributed to routine employment dynamics is not simply a proxy for industrial shifts or the changing educational composition of the economy.

Here we provide additional evidence and discuss related literature regarding the role of routine job loss in jobless recoveries. We begin with state-level evidence for the United States, and conclude with evidence from an international sample of industrialized economies that have undergone job polarization in the past thirty years.

\section{A. State-Level Evidence}

We ask whether the pre- and postpolarization differences of section III, observed in the aggregate, are evident at the finer U.S. state level of aggregation. Unsurprisingly, there is a great deal of heterogeneity in economic performance across the fifty U.S. states. As a result, the national recessions considered so far are not necessarily reflected in output and employment statistics for all states. ${ }^{14}$ We therefore focus on the two largest recessions, the 1982 and 2009 "episodes," to maximize the power of the pre- and postpolarization comparison.

We use state-level data on RGDP and per capita employment. In a manner analogous to the NBER Dating Committee,

this group has risen $7 \%$ since 1990 . However, it has risen only in nonroutine occupations (by 24\%); routine employment has actually fallen $7 \%$ for the same college group, reflecting polarization among these relatively high-educated workers. See also the discussion in Autor et al. (2003).

${ }^{14}$ For instance, the oil and gas boom meant North Dakota avoided recession during the 2009 episode. 
TABle 2.-Employment Recoveries at the State LeVEL

\begin{tabular}{lrrr}
\hline \hline & $\begin{array}{c}\text { 25th } \\
\text { Percentile }\end{array}$ & $\begin{array}{c}\text { 75th } \\
\text { Pedian } \\
\text { Percentile }\end{array}$ \\
\hline A. 1982 & & & \\
$\quad$ Routine share of total loss & 0.51 & 1.10 & 1.39 \\
$\quad$ Total recovery versus loss & 0.83 & 1.56 & 2.42 \\
$\quad$ Routine recovery versus loss & 0.93 & 1.41 & 2.18 \\
B. 2009 & 0.83 & 0.93 & 1.10 \\
Routine share of total loss & -0.38 & -0.25 & -0.01 \\
Total recovery versus loss & -0.53 & -0.18 & 0.02 \\
Routine recovery versus loss & 0.95 & 1.28 & 1.44 \\
$\quad$ Counterfactual recovery versus loss & & & \\
\hline Actual data from the CPS. Counterfactual described in online appendix B.
\end{tabular}

we determine whether a state experienced a recession coincident with the macrolevel episode and, if so, assign statespecific peak and trough dates. Overall, we identify 34 states as experiencing recession during the 1982 episode and 35 states during the 2009 episode (the specific states and details of approach are discussed in online appendix B).

Section IIIB demonstrates that recessions in per capita employment in the aggregate are due almost exclusively to routine occupations. This is true at the state level as well. The first row of table 2, panel A, considers this for the 1982 recession, using the fraction of total job loss that is accounted for by job loss in routine occupations. Given the distribution of outcomes across states, we report the median fraction along with the interquartile range. For the median state that experienced recession during the 1982 episode, $110 \%$ of the state's per capita employment contraction was due to routine job loss. This fraction ranges from $51 \%$ at the 25 th percentile to $139 \%$ at the 75th percentile. Moreover, state-level employment recovered following the cyclical trough in the 1982 episode. Row 2 reports the ratio of per capita employment gain in the two years following the trough, relative to the state's peakto-trough employment loss. For the median state, per capita employment gains were $156 \%$ of its losses during the recession, with interquartile range of $83 \%$ to $242 \%$. Prior to the job polarization era, employment recovered following recessions in the aggregate and at the state level.

Importantly, this recovery was accompanied by recovery of employment in routine occupations. Row 3 of table 2 reports the same ratio as in the second row, but only for routine employment. At the median, (two-year) per capita routine employment gains were $141 \%$ of losses incurred during recession. Indeed, out of the total employment gained in the two years following the median state's trough, $134 \%$ of it was accounted for by gains in routine occupations. This last result is not reported in the table since the analogous statistic cannot be reported for the postpolarization episode, as will become clear.

In the 2009 episode, again, the bulk of total employment lost at the state level is accounted for by routine employment. The first row of panel B indicates that for the median state, $93 \%$ of its per capita employment contraction was due to routine job loss. This corresponds closely to the value of $94 \%$ observed at the national level.
Nationally, the recovery was jobless, and this is true at the state level as well. The second row of panel B considers the ratio of a state's employment gain in the two years following recession, relative to its recessionary loss. The interquartile range is negative: for most states, total per capita employment continued to decline after the recession ended. Gains were experienced in only eight states in the two years following their cyclical trough, and in no state did per capita employment return to its prerecession peak.

Moreover, this lack of recovery in total employment is mirrored by a lack of recovery in routine employment. Row 3 of table 2, panel B, reports the ratio of per capita employment gain in routine occupations during the two years after the trough relative to routine employment loss in the recession. Again, for the majority of states, routine employment continued to decline following the end of the recession.

To quantify the role of routine employment dynamics in the 2009 jobless recovery at the state level, we conduct a counterfactual exercise similar to that of section IIIC for the aggregate economy. We ask what would have happened in 2009 if the postrecession behavior of routine employment had resembled that following the 1982 recession. To do this, we replace the ratio of per capita routine employment gains following the trough relative to losses during the 2009 recession, with the analogous ratio observed in 1982 . We then sum up the actual employment in nonroutine occupations with the counterfactual employment in routine occupations to obtain a counterfactual total employment at the state level, two years following the trough (see online appendix B for a more detailed description).

Had states' employment in routine occupations recovered as they did following the 1982 recession, there would not have been jobless recoveries following 2009. The final row of table 2 reports the ratio of counterfactual per capita employment gain in the two years following the trough, relative to the state's (actual) peak-to-trough employment loss. For the median state, per capita employment gains would have been $128 \%$ of its losses during the recession. This ranges from $95 \%$ at the 25 th percentile to $144 \%$ at the 75 th percentile.

\section{B. International Evidence}

Goos et al. (2014; hereafter, GMS) document the pervasiveness of job polarization in Western European countries, in data beginning in the 1990s. Building on this, we consider whether the nature of economic recoveries has changed in these countries.

Of the sixteen countries studied by GMS, we are able to obtain quarterly data for aggregate employment and RGDP for fourteen of them (Greece and Luxembourg were the exceptions), from 1971 to 2012. From these data, we generate business cycle peak and trough dates to identify the onset and end of recessions (see online appendix B for details). Observations are grouped together based on their timing relative to 1990, which, following GMS, we use to delineate the onset 
Table 3.-Employment and Output Recoveries: Pre- And Postuob POLARIZATION

\begin{tabular}{|c|c|c|c|}
\hline & \multicolumn{2}{|c|}{ Means } & \multirow{2}{*}{$\frac{H_{0}: \text { pre }=\text { post }}{p \text {-Value }}$} \\
\hline & Pre-1990 & Post-1990 & \\
\hline \multicolumn{4}{|l|}{ A. International } \\
\hline Employment & $\begin{array}{l}+1.44 \\
(5.18)\end{array}$ & $\begin{array}{l}-0.73 \\
(2.44)\end{array}$ & 0.036 \\
\hline Output & $\begin{array}{l}+1.61 \\
(1.09)\end{array}$ & $\begin{array}{l}+1.51 \\
(2.12)\end{array}$ & 0.445 \\
\hline \multicolumn{4}{|l|}{ B. United States } \\
\hline Employment & $\begin{array}{c}+0.41 \\
(0.45)\end{array}$ & $\begin{array}{l}-0.45 \\
(0.15)\end{array}$ & 0.006 \\
\hline Output & $\begin{array}{c}+1.94 \\
(0.90)\end{array}$ & $\begin{array}{c}+1.76 \\
(2.08)\end{array}$ & 0.424 \\
\hline
\end{tabular}

International data from Federal Reserve Bank of St. Louis, Federal Reserve Economic Data; and International Monetary Fund, International Financial Statistics. U.S. data from the CPS and NIPA. See appendix A for details.

of job polarization in our sample. We then test whether there has been a change in the nature of employment recoveries relative to output recoveries across time periods. We cannot measure the joblessness of recoveries based on speed, since employment fails to meet standard recovery criteria in an appreciable number of episodes. As such, we use a measure of the strength of recovery within a fixed time window: the four-quarter growth of employment (and output) following recession, normalized by the employment (output) that was lost during the recession. ${ }^{15}$ In all of our analysis, employment and output are expressed in per capita terms.

Panel A of table 3 presents the results of this analysis. The first two columns of the first row present the strength of employment recoveries, averaged across the pre-1990 and post-1990 recession episodes, respectively. There has been a marked fall in the recovery of employment since job polarization. In fact, while employment would expand (on average) following early recessions, employment now continues to decline during the first four quarters of recovery. The right-most column tests the null hypothesis of equality of means across periods, relative to the alternative hypothesis that there has been a fall in the strength of recovery since 1990. For employment, the null is rejected at the $5 \%$ level.

By contrast, there has been essentially no change in the strength of output recoveries. The null hypothesis of equality of means across periods cannot be rejected at standard significance levels. Moreover, in terms of point estimates, the fall in the strength of output recoveries across time periods

\footnotetext{
${ }^{15}$ Note that this measure differs from that of Gali, Smets, and Wouters (2012), who simply consider employment and output growth in the four quarters after recession and ask whether these have changed since 1990. Normalization is important because the severity of recessions has varied over time. To see why this matters, consider two examples. In recession 1, employment falls 5\% during the recession and expands 5\% during the first year of recovery; in recession 2, employment falls $1 \%$ during the recession and expands $1 \%$ during the first year of recovery. By simply measuring postrecession growth, the recovery from recession 2 would be deemed weak or jobless relative to recession 1 , even though both regained all of their recessionary losses in the same time period. In order for recovery growth rates to be meaningful, they must be compared to the size of loss during recession.
}

(0.094) is at least an order of magnitude smaller than the fall for employment (2.18).

To put these results in perspective, panel B of table 3 repeats this analysis for the eleven postwar U.S. recessions considered by Gali et al. (2012). Whereas employment would rebound following early recessions, it now continues to decline during recovery. Again, there has been a clear fall in the strength of employment recoveries since 1990 that is significant at the $1 \%$ level. By contrast, there is no statistically significant evidence for a change in the strength of output recovery over time. Hence, in both the United States and the international sample, the job polarization era has realized the emergence of jobless recoveries.

\section{Subsequent Literature}

Since the first working paper version of this study was written in 2012, a number of papers have extended our results along several dimensions. ${ }^{16}$ Furukawa and Toyoda (2013) replicate our findings linking job polarization and jobless recoveries in Japan. Gaggl and Kaufman (2015) develop a methodology to categorize occupations, involving the estimation of a dynamic factor model on occupational data. This allows for the classification of occupations, based not on tasks but solely on the time series properties of occupational employment, into two groups that "almost perfectly coincide with 'routine' and 'non-routine' occupations," and the identification of group-specific structural breaks in employment. Their analysis finds a "strong tie between the well documented polarization trend and employment dynamics over the business cycle. . . . Aggregate employment per capita would have recovered significantly more strongly in the absence of the observed structural change around 1990."

Burger and Schwartz (2018) also consider the link between the disappearance of routine jobs and jobless recovery among U.S. states, though their methodology differs from that presented above. They identify recessions using data on personal income and GDP, and consider a larger number of state-level episodes, including those that do not correspond to recessions at the national level. Their probit analysis finds strong and statistically significant evidence that "routine-replacing technological change has contributed to the jobless recovery phenomenon." Specifically, the greater the long-run decline of routine employment share (as obtained from an HP-filtered trend) at the onset of recession, the greater the probability of jobless recovery.

A number of papers have also explored our hypothesis in cross-country data. Gaggl and Kaufman (2015) consider a sample of sixteen (non-U.S.) industrialized economies using the EU KLEMS database. As with the results reported above, international comparisons are hindered by the lack

\footnotetext{
${ }^{16}$ While we focus our discussion on empirical work related to this paper, we note that a number of other papers have studied the quantitative theoretical link between polarization and business cycle dynamics. See, for instance, Kopytov, Roussanov, and Taschereau-Dumouchel (2018).
} 
of comprehensive occupation-level data and the task content of occupations, as in the United States; as such, Gaggl and Kaufman (2015) consider polarization dynamics by delineating employment across high-, middle-, and low-skill groups. They find that employment recoveries have become slower relative to output recoveries during the (country-specific) job polarization era, though the slowdown is not as pronounced as in the United States. Graetz and Michaels (2017) consider industry-level (as opposed to occupation-level) data in the same international sample. They find that since 1985, industries that are more routine intensive did not experience significantly slower employment recoveries than less routineintensive industries did. This is in contrast to their findings for the United States, where cross-industry variation in routine intensity does explain variation in the joblessness of recovery. We conclude that the link between jobless recoveries and the disappearance of routine employment as a worldwide phenomenon deserves further study and would benefit from the compilation of internationally comparable data on occupational tasks and employment.

\section{Conclusion}

In the past 35 years the U.S. labor market has been characterized by job polarization and jobless recoveries. In this paper, we demonstrate how these are related. We first show that the loss of middle-skill employment in routine occupations is concentrated in economic downturns. Second, we show that the disappearance of routine employment accounts for jobless recoveries. This is based on the fact that almost all of the contraction in aggregate employment during recessions can be attributed to job losses in routine occupations, which account for a substantial fraction of total employment, and that jobless recoveries are observed only in these disappearing jobs since polarization began. Moreover, the role attributed to routine employment dynamics is not simply a proxy for the role of industrial shifts or the changing educational composition of the economy. We supplement the aggregate evidence with state-level evidence from the United States and evidence from a sample of international countries that have undergone job polarization. In all cases, we find clear evidence for the link between job polarization and jobless recoveries.

\section{REFERENCES}

Aaronson, Daniel, Ellen R. Rissman, and Daniel G. Sullivan, "Can Sectoral Reallocation Explain the Jobless Recovery?" Economic Perspectives, Federal Reserve Bank of Chicago 28:2 (2004), 36-49.

Acemoglu, Daron, "Changes in Unemployment and Wage Inequality: An Alternative Theory and Some Evidence," American Economic Review 89 (1999), 1259-1278.

Acemoglu, Daron, and David Autor, "Skills, Tasks and Technologies: Implications for Employment and Earnings" (pp. 1043-1171), in Orley Ashenfelter and David Card, eds., Handbook of Labor Economics, vol. 4B (Amsterdam: Elsevier, 2011).

Autor, David, The Polarization of Job Opportunities in the U.S. Labor Market: Implications for Employment and Earnings (Washington, DC: Center for American Progress and the Hamilton Project, 2010).

Autor, David H., and David Dorn, "The Growth of Low Skill Service Jobs and the Polarization of the US Labor Market," American Economic Review 103 (2013), 1553-1597.
Autor, David H., Lawrence F. Katz, and Melissa S. Kearney, "The Polarization of the U.S. Labor Market," American Economic Review: Papers and Proceedings 96 (2006), 189-194.

Autor, David H., Frank Levy, and Richard J. Murnane, "The Skill Content of Recent Technological Change: An Empirical Exploration," Quarterly Journal of Economics 118 (2003), 1279-1333.

Bachmann, Ruediger, "Understanding the Jobless Recoveries after 1991 and 2001," University of Notre Dame, unpublished manuscript (2012).

Berger, David, "Countercyclical Restructuring and Jobless Recoveries," Northwestern University, working paper (2012).

Bernanke, Ben S., "The Jobless Recovery" (2003), http://www.federal reserve.gov/boarddocs/speeches/2003/200311062/default.htm.

"On the Outlook for the Economy and Policy" (2009), http://www .federalreserve.gov/newsevents/speech/bernanke20091116a.htm.

Brynjolfsson, Erik, and Andrew McAfee, Race against the Machine: How the Digital Revolution Is Accelerating Innovation, Driving Productivity, and Irreversibly Transforming Employment and the Economy (Digital Frontier Press, 2011).

Burger, John D., and Jeremy S. Schwartz, "Jobless Recoveries: Stagnation or Structural Change?" Economic Inquiry 56 (2018), 709-723.

Charles, Kerwin K., Erik Hurst, and Matthew J. Notowidigdo, "Housing Booms, Manufacturing Decline and Labour Market Outcomes," Economic Journal 129 (2019), 209-248, https://onlinelibrary.wiley .com/doi/abs/10.1111/ecoj.12598.

Christiano, Lawrence J., and Terry J. Fitzgerald, "The Band Pass Filter," International Economic Review 44 (2003), 435-465.

Cortes, Guido Matias, "Where Have the Middle-Wage Workers Gone? A Study of Polarization Using Panel Data," Journal of Labor Economics 34 (2016), 63-105.

Cortes, Guido Matias, Nir Jaimovich, Christopher J. Nekarda, and Henry E. Siu, "The Micro and Macro of Disappearing Routine Jobs: A Flows Approach," University of British Columbia working paper (2016).

Firpo, Sergio, Nicole M. Fortin, and Thomas Lemieux, "Occupational Tasks and Changes in the Wage Structure," University of British Columbia unpublished manuscript.

Furukawa, Yosuke, and Hiroki Toyoda, "Job Polarization and Jobless Recoveries in Japan: Evidence from 1984 to 2010,” KIER discussion paper 874 (2013).

Gaggl, Paul, and Sylvia Kaufman, "The Cyclical Component of Labor Market Polarization and Jobless Recoveries in the US," University of North Carolina at Charlotte working paper (2015).

Gali, Jordi, Frank Smets, and Rafael Wouters, "Slow Recoveries: A Structural Interpretation," Journal of Money, Credit and Banking 44: Suppl. 2 (2012), 9-30.

Goos, Maarten, and Alan Manning, "Lousy and Lovely Jobs: The Rising Polarization of Work in Britain," this REVIEW 89 (2007), 118-133.

Goos, Maarten, Alan Manning, and Anna Salomons, "Job Polarization in Europe," American Economic Review: Papers and Proceedings 99 (2009), 58-63.

"Explaining Job Polarization: Routine-Biased Technological Change and Offshoring," American Economic Review 104 (2014), $2509-2526$.

Gordon, Robert J., and Martin Neil Baily, "The Jobless Recovery: Does it Signal a New Era of Productivity-Led Growth?" Brookings Papers on Economic Activity 1993 (1993), 271-316.

Graetz, Georg, and Guy Michaels, "Is Modern Technology Responsible for Jobless Recoveries?" American Economic Review Papers and Proceedings 107 (2017), 168-173.

Groshen, Erica L., and Simon Potter, "Has Structural Change Contributed to a Jobless Recovery?" Current Issues in Economics and Finance, Federal Reserve Bank of New York 9:8 (2003), 1-7.

Koenders, Kathryn, and Richard Rogerson, "Organizational Dynamics over the Business Cycle: A View on Jobless Recoveries," Federal Reserve Bank of St. Louis Review (July/August 2005), 555-580.

Kopytov, Alexandr, Nikolai Roussanov, and Mathieu TaschereauDumouchel, "Short-Run Pain, Long-Run Gain? Recessions and Technological Transformation," Journal of Monetary Economics 97 (2018), 29-44

Meyer, Peter B., and Anastasiya M. Osborne, "Proposed Category System for 1960-2000 Census Occupations," Bureau of Labor Statistics working paper 383 (2005)

Rytina, Nancy F., and Suzanne M. Bianchi, "Occupational Reclassification and Changes in Distribution by Gender," BLS Monthly Labor Review 107 (1984), 11-17. 
Schreft, Stacey L., and Aarti Singh, "A Closer Look at Jobless Recoveries," Economic Review, Federal Reserve Bank of Kansas City Second Quarter (2003), 45-72.

Stein, Robert L., "New Definitions for Employment and Unemployment," Employment and Earnings and Monthly Report on the Labor Force 14 (1967), 3-27.

\section{Appendix A}

\section{Data Sources}

A. U.S. Macroeconomic Data. The population measure is the civilian noninstitutional population, 16 years and over, from the Current Population Survey, Bureau of Labor Statistics. Aggregate employment is total employment within this population. Estimates of RGDP at a monthly frequency are those of James Stock and Mark Watson (http://www .princeton.edu/ mwatson/mgdp_gdi.html). These data end in June 2010; data from July 2010 are interpolated from quarterly RGDP data taken from the FRED Database, Federal Reserve Bank of St. Louis.

In section IIID, data for industrial employment are from the Current Employment Statistics survey of the BLS, taken from the FRED Database. Aggregate employment refers to "all employees: total nonfarm," manufacturing employment is "all employees: manufacturing," and construction employment is "all employees: construction." Data for employment delineated by education and occupation are from 1989 to 2012 and were obtained from the Basic Monthly Files of the CPS, from the NBER website.

B. Employment Data by Occupation. We consider an occupational classification system that provides ease of data access and replication and allows for the most comprehensive time series coverage possible, extending back to 1967. Beginning in 1983, our classification is based on the categorization of occupations in the 2000 Standard Occupational Classification system. Specifically, data for January 1983 to December 2013 are taken from FRED. Nonroutine cognitive workers are those employed in "management, business, and financial operations occupations" and "professional and related occupations." Routine cognitive workers are those in "sales and related occupations" and "office and administrative support occupations." Routine manual occupations are "production occupations," "transportation and material moving occupations," "construction and extraction occupations," and "installation, maintenance, and repair occupations." Nonroutine manual occupations are "service occupations."

Data on employment at the occupational group level from July 1967 to December 1982 are taken from Employment and Earnings, Bureau of Labor Statistics, various issues. Nonroutine cognitive workers are those employed in "professional and technical" and "managers, officials, and proprietors" occupations. Routine cognitive workers are those classified as "clerical workers" and "sales workers." Routine manual workers are "craftsmen and foremen," "operatives," and "nonfarm labourers." Nonroutine manual workers are "service workers." "Farm workers" (farmers, farm managers, farm laborers, and farm foremen) are excluded from the employment data at the occupational level.

Finally, we note that employment at the occupational group level displays a break between 1982 and 1983. This is due to the extensive reclassification of occupations undertaken with the 1980 Census codes (see, e.g., Rytina \& Bianchi, 1984, and Meyer \& Osborne, 2005), and implemented in the CPS beginning in January $1983 .{ }^{17}$ As such, we have adjusted the data prior to 1983 to remove the discontinuity. Because the adoption of the 1980 occupation codes occurs only one month from the start of the recovery following the 1982 recession (with the recessionary trough dated as November 1982 by the NBER), the timing of the break does not affect our analysis regarding the nature of recoveries in employment.

C. Section IV Data. High-frequency state-level data do not exist for both pre- and postpolarization periods. As such, we use annual data on RGDP from the Regional Economic Accounts of the BEA (bea.gov/data/gdp/gdp-state). Per capita employment data are obtained from the CPS. In terms of international data, quarterly RGDP, the quarterly data for aggregate employment and RGDP are from the OECD and were obtained from the FRED Database. For thirteen of the fourteen countries, aggregate employment refers to civilian employment; the exception is Belgium, where only total employment is available. To derive per capita measures, data for adult population to were taken from the IMF, International Financial Statistics.

\section{Appendix B}

\section{Counterfactuals}

Using the data for routine occupations displayed in figure 5 , we derive the percentage deviation in employment for the 24 months following the trough of each of the early recessions. We then take the average of these deviations and refer to this as the "average response" of routine employment during early recoveries. This is displayed as the (last half of the) solid line in the upper-left panel of figure B1. In the 1991, 2001, and 2009 recessions, we replace the post-trough dynamics of routine employment with a rescaled version of the average response. In particular, we rescale the average response to match the magnitude of the fall in actual routine employment within the first five months of the trough. We choose five months, since this is the turning point of the average response.

The counterfactual for routine employment is displayed for the example of the 2009 recession as the hatched line in the upper-left panel of figure B1. Because the actual fall after the 2009 trough was greater than that in the average of the early recessions, the average response had to be magnified.

\footnotetext{
${ }^{17}$ This is true of any occupational classification system, including the one we consider and that of Autor and Dorn (2013).
} 
Figure B1.-Constructing Counterfactual EMPloyment
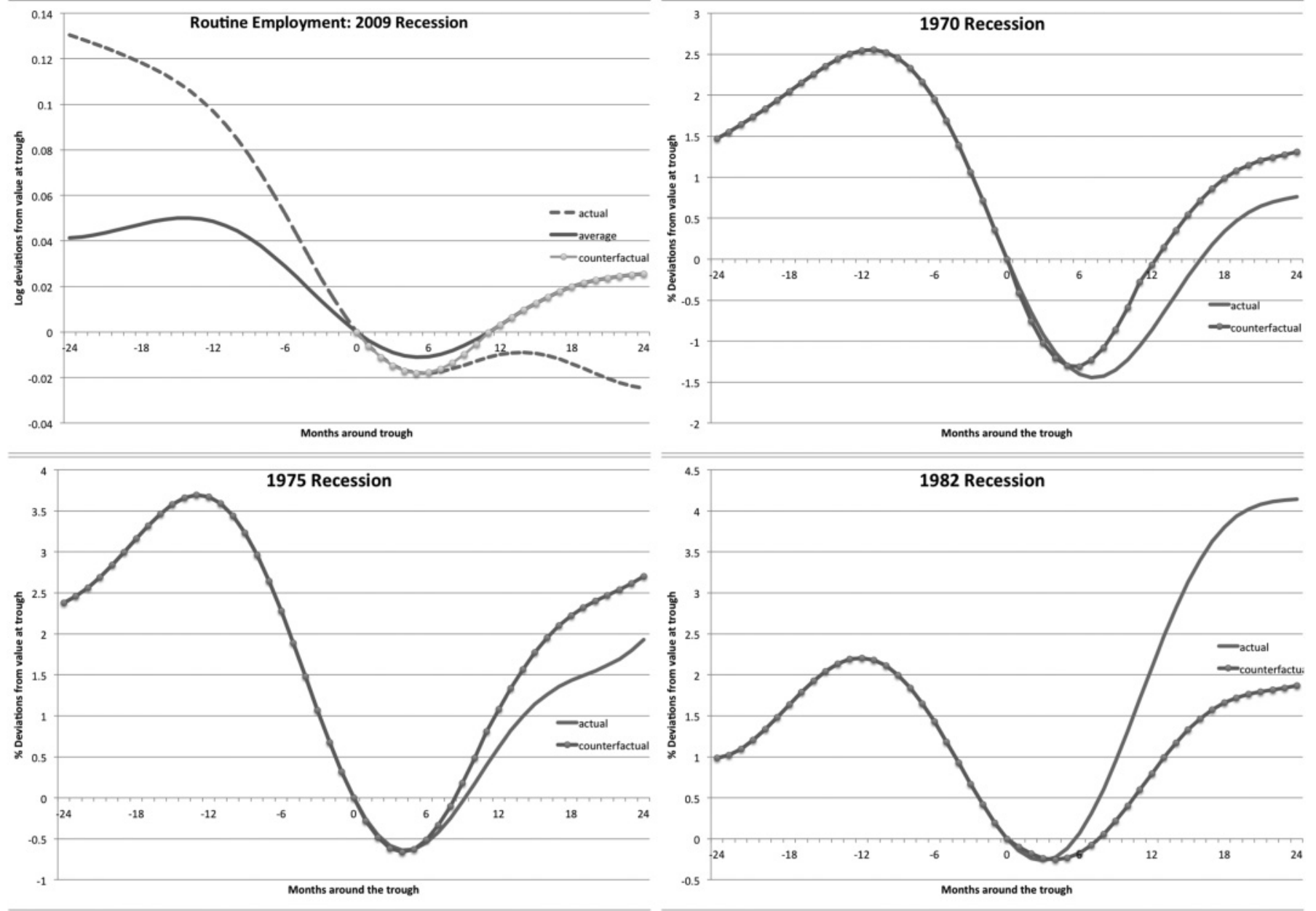

Data from the Bureau of Labor Statistics, Current Population Survey. See appendix A for details.

After 11 months, the average response turns positive. The magnification factor would then imply a very sharp rebound in the counterfactual. Hence, to be conservative, we set the counterfactual for months 12 through 24 to be exactly the average response. In the cases of the 1991 and 2001 recessions, the average response fell more sharply than did actual routine employment. In these cases, the counterfactual was derived by attenuating the average response by the appropriate factor. To be conservative on the strength of the recovery, after the average response turns positive, we maintained the attenuation factor.

These counterfactuals in log deviations were then used to derive counterfactuals for routine employment levels. These

were then added to the actual employment levels in nonroutine occupations to obtain counterfactual aggregate employment series. These counterfactuals in the aggregate were then expressed as log deviations from their value at the recession troughs to obtain figure 7 .

Finally, in the upper-right, lower-left panel, and lower-right panels of figure B1, we present the results of the same counterfactual experiment for the 1970, 1975, and 1982 recessions. These panels demonstrate that the nature of the early recoveries, which were not jobless, is not fundamentally altered by the exercise. That is, they continue to display recoveries in aggregate employment with roughly the same magnitude and timing. 